\title{
Paravertebral muscles in disease of the cervical spine
}

\author{
S B Wharton, K K Chan, J D Pickard, J R Anderson
}

\begin{abstract}
Objectives-Cervical spine disorders are common in the older population. The paravertebral muscles are essential to the support and stabilisation of the cervical spine but have been little studied. The aim was to determine whether pathological changes develop in these muscles in patients with severe cervical spine disease, which, if present, might contribute to the pathogenesis and symptomatology of their disorder.
\end{abstract}

Methods-Open biopsies of superficial and deep paravertebral muscles were obtained during the course of surgical procedures to alleviate cervical myelopathy. Most of these patients had cervical spondylosis or rheumatoid arthritis involving the cervical spine. The biopsies were compared with muscle obtained at necropsy from patients without a history of cervical spine or neuromuscular disorder.

Results-Muscle from both the study and control groups showed a similar range and severity of abnormalities. In several patients, grouped fibre atrophy suggested chronic partial denervation. Most biopsies showed type 1 fibre predominance and selective type 2 fibre atrophy. Ragged red fibres were a frequent finding and electron microscopy disclosed accumulations of mitochondria, a small proportion of which contained rounded, or longitudinally oriented, single osmiophilic inclusions. Fibres containing core-like areas were also frequent. These pathological features were seen with increasing severity and frequency with increasing age.

Conclusions-The paravertebral cervical muscles develop pathological abnormalities with increasing age with both neurogenic and myopathic features, the pathogenesis of which is probably multifactorial. Such a muscle disorder would be expected to be accompanied by functional impairment which may contribute to the development and symptomatology of cervical spine disease with increasing age.

$(\mathcal{F}$ Neurol Neurosurg Psychiatry 1996;61:461-465)

Keywords: paravertebral muscles; cervical spine disease; age related myopathy

Diseases of the cervical and lumbar spine are a common cause of symptoms and loss of work- ing days, particularly in people over the age of 50. In a small proportion of patients the disease is sufficiently severe that neurological abnormalities develop. ${ }^{1}$ The spine is amenable to several imaging modalities including myelography, CT, MRI, and discography, ${ }^{23}$ but the supporting soft tissues, in particular the paravertebral muscles, have been little studied. Inflammatory or degenerative diseases of joints and ligaments are the chief causes of vertebral instability, but the role of the musculature in the support of the spine is revealed in patients with Duchenne dystrophy and spinal muscular atrophy, who develop severe spinal deformities at a young age. ${ }^{4-6}$ Furthermore, in patients with spinal disease, attention has been focused on the importance of the state of the supporting musculature by studies showing the beneficial effects of exercise in patients with spinal disease. ${ }^{78}$

This study was undertaken to determine whether appreciable pathological changes were present in the paravertebral muscles of patients with severe cervical spine disease. Such changes, if present, whether arising secondary to the disease of the spine, or primarily as a result of aging, might contribute to the pathogenesis and symptomatology of disorders of the cervical spine. We have studied the paravertebral muscles in patients with cervical spine disease of sufficient severity to require surgery. As a control group we have studied an unselected necropsy population with no history of cervical spine disease or of neuromuscular disorders.

\section{Patients and methods}

The study group comprised 15 patients (11 women, four men) with a mean age of 66 (range 45 to 81 ) years. All of these patients were operated on because of severe cervical spine disease with neurological and radiological abnormalities. The underlying disease process in most patients was either rheumatoid arthritis (eight patients) or cervical spondylosis (five patients). One patient was operated on for a post-traumatic $\mathrm{C} 4 / 5$ spondylolisthesis and one patient for cervical spine destabilisation due to a solitary metastasis (adenocarcinoma). In most patients the focus of disease was in the mid-cervical region (C3 to C6). In two patients with degenerative disease the focus of disease was in the upper cervical spine (atlantoaxial and $\mathrm{C} 2 / 3$ ).

The control group comprised an unselected necropsy population of 23 patients (nine women, 14 men) with a mean age of 67 (range 


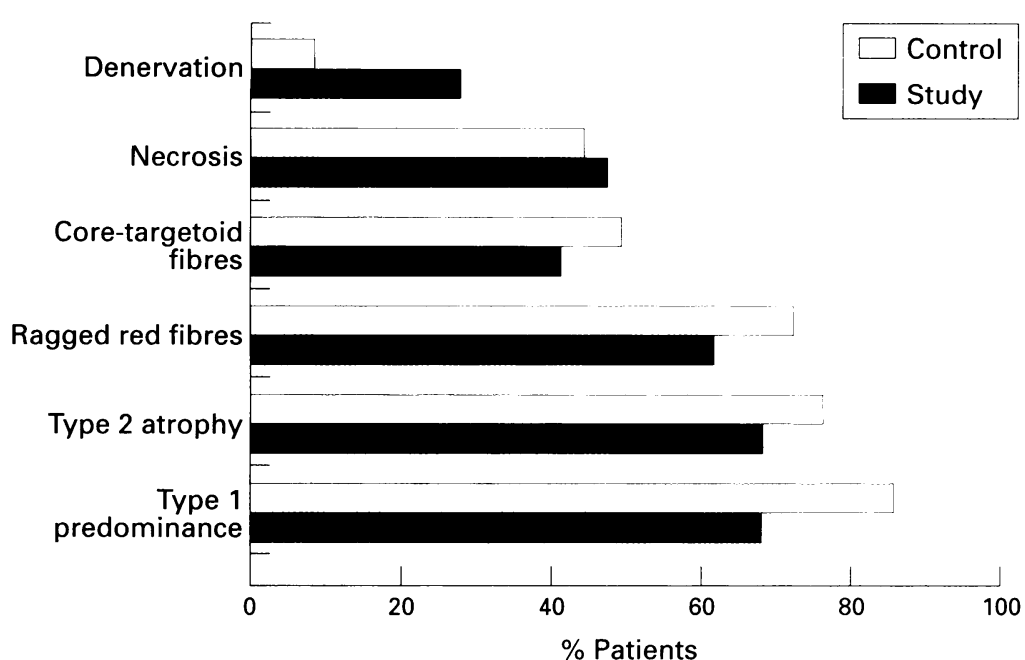

Figure 1 Nature and frequency (\% patients) of pathological features found in the biopsies from the study and control groups.

\section{Results}

Muscle biopsies from both the study and control groups showed a high prevalence of pathological abnormalities. The features described below were seen in both groups with a similar prevalence and severity (fig 1). Most patients showed predominance of type 1 fibres. Selective type 2 fibre atrophy, assessed subjectively, was found in $60 \%-70 \%$ of patients and was, in some patients, very severe. Evidence of denervation, in the form of grouped atrophy and angular atrophic fibres, was seen in four and two patients in the study and control groups respectively.

Ragged red fibres were seen in $60 \%-70 \%$ of patients in both groups (Fig 2A). These fibres showed an excess of lipid and stained intensely with NADH-TR. Several patients showed fibres with a negative cytochrome oxidase reaction, particularly when many ragged red fibres were present. Some of the ragged red fibres were themselves negative for cytochrome oxidase activity (fig $2 \mathrm{~B}$ ), although others had a positive rim.

Core-targetoid fibres were seen in $40 \%-$ $50 \%$ of patients in both groups, consisting of rounded areas of absent reactivity on histochemical preparations for NADH-TR (fig $2 \mathrm{C})$. In most of these patients they were present in $10 \%$ to $20 \%$ of the fibres, ranging from less than $5 \%$ to about $30 \%$ of fibres. In one patient in the study group, nemaline rods were seen. Scattered necrotic fibres were seen in $40 \%-50 \%$ of patients; these were not associated with inflammation. Inflammation, when present (in $27 \%$ of the study group and $13 \%$ of controls), was mild and focal, consisting of a few chronic inflammatory cells in the endomysium which did not invade muscle fibres.

Electron microscopy confirmed that ragged red fibres represented fibres in which there were subsarcolemmal and intermyofibrillar accumulations of mitochondria. Most of the accumulated mitochondria did not appear morphologically abnormal, but inclusions were seen in a few. The most usual type consisted of single, rounded, amorphous inclusions, sometimes seen in longitudinal section. More rarely, an inclusion with internal structure was found (fig 3A). In patients in whom core-targetoid structures were found, electron microscopy showed fibres with central disruption and streaming of the myofibrillar architecture (Fig 3B)

As noted, the prevalence and severity of these abnormalities were similar in the study and control groups, and in the study group there was little apparent difference between the patients with rheumatoid arthritis and cervical spondylosis. The prevalence of pathological abnormalities increased with age in both groups, being much less in patients under 60 years of age. This was illustrated by an increase in the mean total score of histological abnormalities with age. The increase in pathological findings with age was also reflected in an increased prevalence of patients with ragged red fibres (study group $<59$ years $0 \%$, $>60$ years $75 \%$; control group $<59$ years 


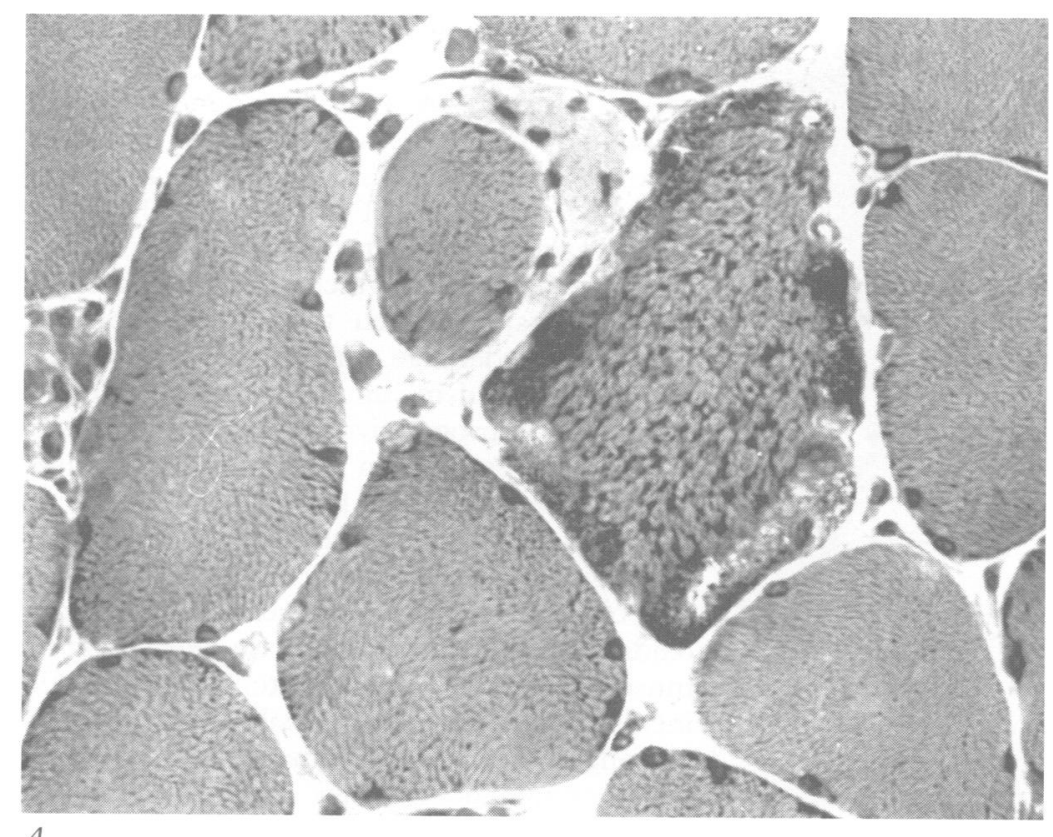

$$
\text { A }
$$
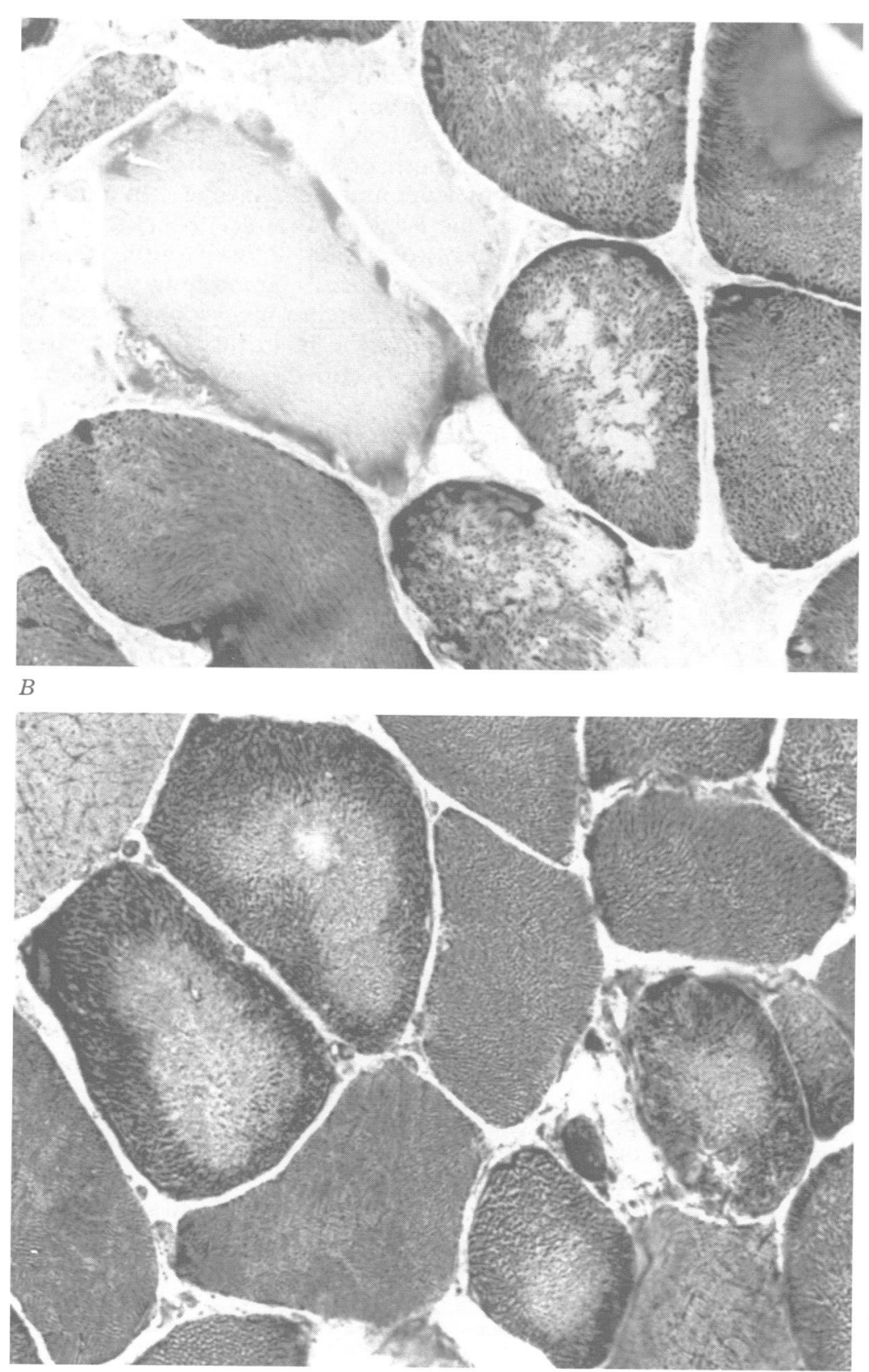

Figure 2 (A) Gomori trichrome preparation showing a "ragged red" muscle fibre, with accumulation of material (red in colour with this preparation) in a subsarcolemmal and intermyofibrillar location. (B) Histochemical

preparation for cytochrome oxidase showing a fibre with the morphology of a "ragged red" fibre, and an adjacent fibre both showing an absent staining reaction. Other fibres in the field show a patchy staining reaction. (C) NADH$T R$ preparation showing core-targetoid fibres with a well demarcated central absence of staining reaction; magnification $\times 280$.

$29 \%,>60$ years $88 \%$ ). The mean percentage of ragged red fibres per muscle also increased with age in both the study and control groups, and indeed was greater in the control group at all ages. The range of values for percentage of ragged red fibres per muscle also increased with age, becoming very wide in the older population, and ranging from several patients with no ragged red fibres to patients with considerable numbers (study group $<59$ years, mean percentage of ragged red fibres per muscle $0 \%$, range $0 \%$, interquartile range (IQR) $0 \%$; study group $>60$ years, mean $1 \cdot 89 \%$, range $0 \%$ $12.38 \%$, IQR $0-1 \cdot 19 \%$; control group $<59$ years, mean $0.17 \%$, range $0 \%-0.77 \%$, IQR $0 \%-0 \cdot 19 \%$; control group $>60$ years, mean $4 \cdot 89 \%$, range $0 \%-34 \cdot 12 \%$, IQR $1 \cdot 07 \%$ $4 \cdot 69 \%)$.

\section{Discussion}

We have shown profound pathological abnormalities in both superficial and deep cervical paravertebral muscle groups. The presence of type 1 predominance is perhaps not surprising in a group of muscles with a largely postural function. The presence of denervation in several patients, indicated by angular atrophic fibres and grouped atrophy, can probably be accounted for by nerve root compression due to bony abnormalities of the cervical spine. Core-targetoid fibres, present in a higher proportion of patients, may also reflect denervation. In addition to these findings, however, there is a high prevalence of myopathic features, including type 2 fibre atrophy, ragged red fibres, and scattered necrotic fibres.

The prevalence and severity of these abnormalities was similar in both the study group and the control necropsy population. Indeed, although a slightly higher proportion of the study group showed denervation changes, the prevalence of other abnormalities such as ragged red fibres, was higher in the control group. A necropsy group is, clearly, not the perfect control (an age and sex matched, otherwise well population, biopsied in life with imaging established healthy cervical spines), and some may have had a degree of cervical spondylosis which is common with increasing age. Nevertheless, our control population had no clinical history of cervical spine disease and none had been subjected to operation for such disease, so that any spinal disease present was certainly much less severe than in the study group. This being the case, our data reject the hypothesis that the pathological changes in the muscles are secondary to the cervical spine disease, there being no difference between the 


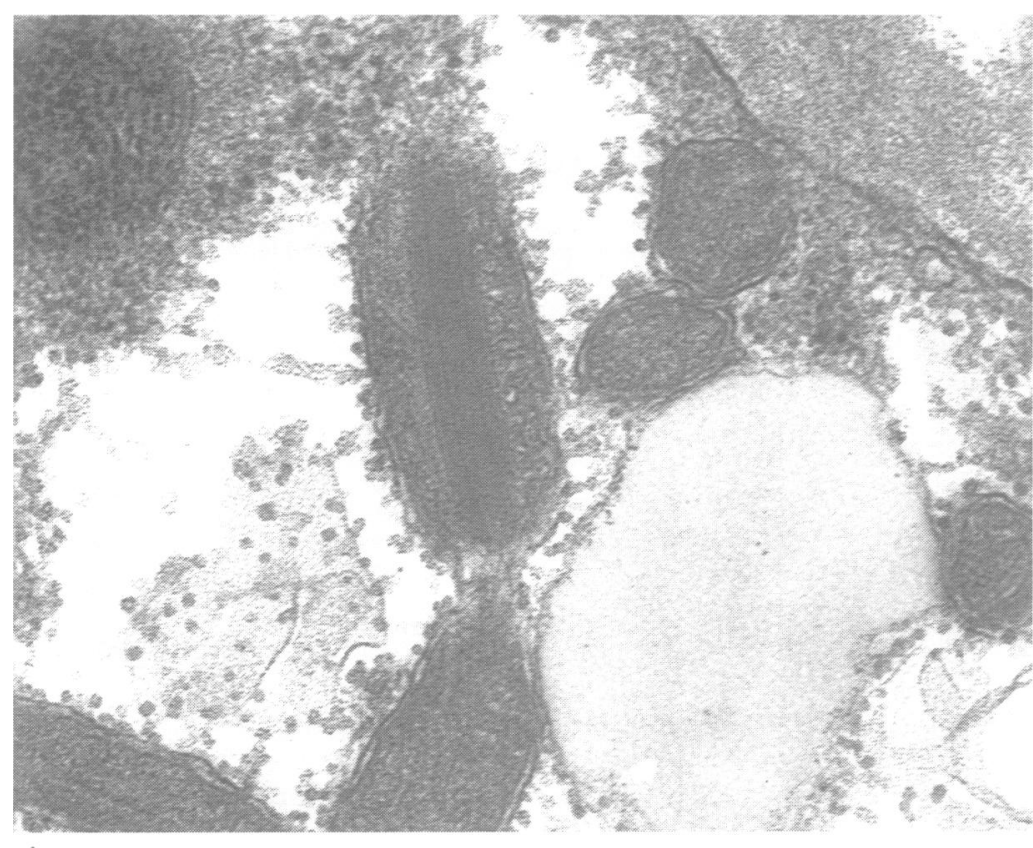

$A$

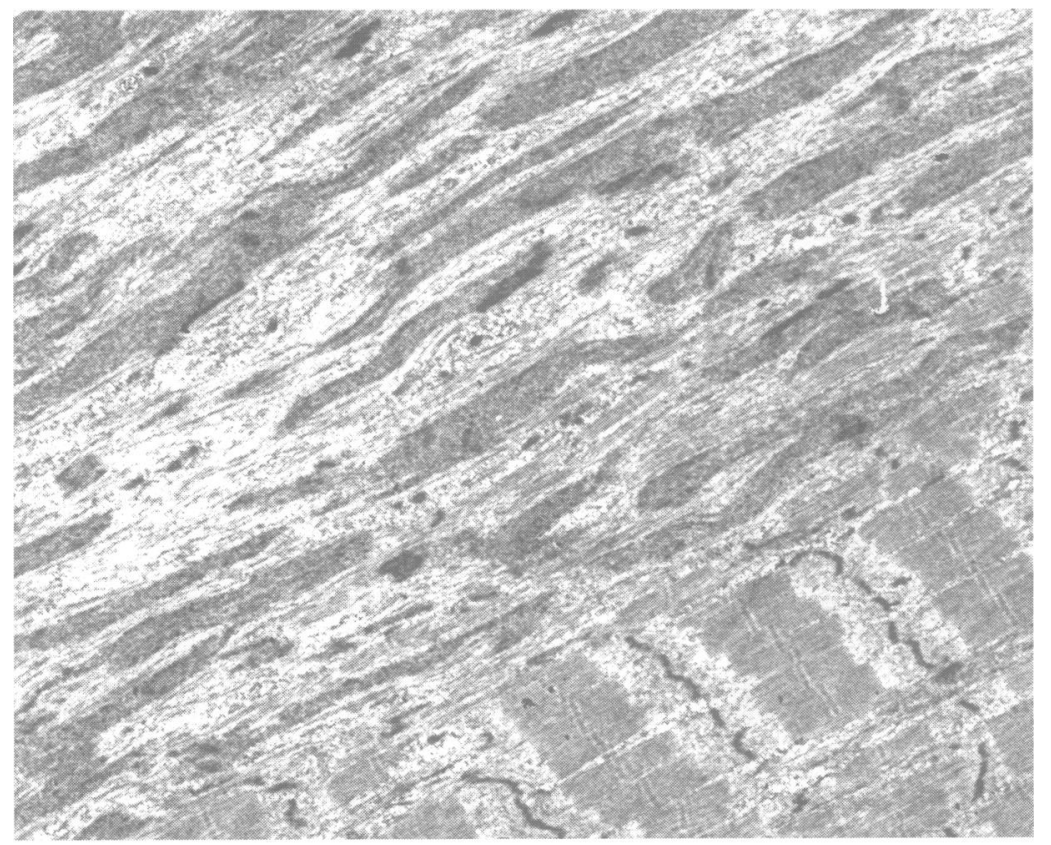

$B$

Figure 3 (A) Electron micrograph shows a mitochondrial inclusion with internal structure. The single inclusion runs the length of the mitochondrion and shows parallel electron dense lines; magnification $\times 50$ 000. (B) Electron micrograph of a muscle fibre showing central myofibrillar streaming; magnification $\times 5800$.

two groups. Rather, in both groups, the pathological abnormalities become more severe and more prevalent with increasing age, so that this seems to be an age related muscle disorder.

Selective type 2 fibre atrophy was a common finding and is a well recognised, non-specific finding with many causes, ${ }^{9}$ which, in our patients, might include various combinations of disuse atrophy, intercurrent illness, and drugs (for example, corticosteroids).

The age related presence of ragged red fibres is a more intriguing finding. These are, of course, associated with primary mitochondrial diseases. ${ }^{10-11}$ However, ragged red fibres occur in other diseases, not primarily consid- ered to be disorders of mitochondrial DNA such as inclusion body myopathy, in which they are associated with mitochondrial DNA deletions. ${ }^{12}$ In this disease the ragged red fibres have been suggested to arise by clonal expansion of mitochondrial DNA with a deletion in regenerating muscle after segmental necrosis. ${ }^{13}$ This is a mechanism which may be relevant to our patients, in which there is evidence of muscle fibre damage. Ragged red fibres have also been found in lumbar spinal muscles of patients with progressive lumbar kyphosis and in patients operated on for lumbar spinal disc disease. ${ }^{14}$ We have also found them in lumbar spinal muscles (unpublished observations) suggesting that they may be a particular feature of aging in postural muscles. Cytochrome oxidase deficient fibres increase with aging in muscle, ${ }^{15}$ and deletions of mitochondrial DNA increase with aging, ${ }^{16-18}$ possibly secondary to prolonged free radical damage. It remains to be determined whether the age related increase in ragged red fibres in the paraspinal muscles in our study is arising secondary to acquired alteration in mitochondrial DNA, or to some other mechanism.

It is also of note that ragged red fibres and core-targetoid fibres, as found in our patients, have both been produced in an experimental model of acute muscle ischaemia. ${ }^{19}$ In particular, in this ischaemic model the ragged red fibres ultrastructurally showed mitochondria containing similar, amorphous, single, rounded electron dense inclusions as seen in our patients, a type of inclusion not, to our knowledge, described in mitochondrial cytopathies.

In conclusion, the paraspinal muscles in both our study group and control group showed increasing pathological abnormalities with age. Both myopathic features and features of denervation were seen, so that this age related muscle disorder may have both a myogenic and neurogenic component. Whatever the precise pathogenesis, it seems probable that such striking pathological findings are associated with functional impairment of this group of muscles with increasing age, and thus may contribute to the pathogenesis and symptomatology of cervical spine disorders and to instability of the cervical spine in those with severe bony disease. The state of these muscles is therefore of clinical relevance and methods to improve their strength may be of value in these patients. Non-invasive methods, such as MRI, do provide information as to the state of musculature, ${ }^{20}$ and may be of value in the assessment and follow up of some of these patients.

We thank Mr G Gatward for excellent technical work in the preparation of material for electron microscopy and $\mathrm{MrC}$ Burton for help with photomicrography.

1 Long DM. Lumbar and cervical spondylosis and spondylotic myelopathy. Curr Opin Neurol Neurosurg 1993;6: 576-80.

2 Perneczky G, Bock FW, Neuhold A, Stiskal M. Diagnosis of cervical disc disease. MRI versus cervical myelograof cervical disc disease. MRI vers
phy. Acta Neurochir 1992;116:44-8.

3 Tournade A, Patay Z, Tajahmady T, Braun JP, Million S, Schmutz G. Contribution of discography to the diagnosis and treatment of lumbar disc herniation. $\mathcal{F}$ Neuroradio 1991;18:1-11. 
4 Gomez MR. The clinical examination. In: Engel AG, Franzini Armstrong C, eds. Myology. 2nd ed. McGraw Hill, 1994:746-63.

5 Brooke MH, Fenichel GM, Griggs RC, et al. Duchenne muscular dystrophy: patterns of clinical progression and muscular dystrophy: patterns of clinical progression and
effects of supportive therapy. Neurology 1989;39:475-81. 6 Dubowitz V, Heckmatt J. Management of muscular dystroDubowitz V, Heckmatt J. Management of muscular dystro-
phy. Pharmacological and physical aspects. Br Med Bull 1980;36:139-44.

7 Frost H, Klaber Moffett JA, Moser JS, Fairbank JCT. Randomised controlled trial for evaluation of fitness programme for patients with chronic low back pain. BMF 1995;310:151-4.

8 Malmivaara A, Hakkinen U, Aro $T$, et al. The treatment of acute low back pain-bed rest, exercises, or ordinary activity? N Engl F Med 1995;332:351-5.

9 Banker BQ, Engel AG. Basic reactions of muscle. In: Engel AG, Franzini Armstrong C, eds. Myology. 2nd ed. AG, Franzini Armstrong

10 Yamamoto $M$, Clemens PR, Engel AG. Mitochondrial DNA deletions in mitochondrial cytopathies: observaDNA deletions in mitochondrial cytopathies: 11 Schapira AHV. Mitochondrial cytopathies. Curr Opin

12 Oldfors A, Larsson NG, Lindberg C, Holme E. Mitochondrial DNA deletions in inclusion body myositis. Brain 1993;116:325-36.

13 Oldfors A, Moslemi AR, Fyhr IM, Holme E, Larsson NG,
Lindberg C. Mitochondrial DNA deletions in muscle fibres in inclusion body myositis. $\mathcal{f}$ Neuropathol Exp Neurol 1995;54:581-7.

14 Delisle MB, Laroche M, Dupont H, Rochaix P, Rumeau JL. Morphological analysis of paraspinal muscle: comparison of progressive lumbar kyphosis (camptocormia) and narrowing of lumbar canal by disc protrusions. Neuromuscul Disord 1993;3:579-82.

15 Muller-Hocker J. Cytochrome c oxidase deficient fibres in the limb muscle and diaphragm of man without muscula disease: an age-related alteration. $\mathcal{F}$ Neurol Sci 1990 100:14-21.

16 Corral-Debrinski M, Horton T, Lott MT, Schaffner IM, Flint Beal M, Wallace DC. Mitochondrial DNA deletions in human brain: regional variability and increase with advanced age. Nat Genet 1992;2:324-9.

17 Cortopassi GA, Arnheim N. Detection of specific mitochondrial DNA deletion in tissues of older humans. Nucl Acids Res 1990;18:6927-33.

18 Linnane AW, Marzuki S, Ozawa T, Tanaka M. Mitochondrial DNA mutations as an important contributor to ageing and degenerative disease. Lancet 1989;i:642-5.

19 Heffner RR, Barron SA. The early effects of ischaemia upon skeletal muscle mitochondria. $\mathcal{F}$ Neurol Sci 1978; 38:295-315.

20 Claque JE, Roberts N, Gibson H, Edwards RHT. Muscle imaging in health and disease. Neuromuscul Disord 1995; 5:171-8

\section{NEUROLOGICAL STAMP}

\section{Thomas Sydenham (1624-89)}

The 17th century physician, Thomas Sydenham, became known as the English Hippocrates. He studied medicine at Oxford where the dentist Robert Boyle and the physician and philosopher John Lock were his friends. John Lock gave a detailed account of trigeminal neuralgia in a series of letters in 1667 and Sydenham made contributions to the same condition. Sydenham's education was interrupted by the English Civil War. His father and four brothers were serving in Cromwell's army. Thomas also enlisted and served for four years as Captain of a Troop of Horse after which he returned to Oxford, gaining his MB in 1648. His medical studies continued at Montpellier where Rabelais (1490-1553) had earlier been Professor of Medicine.

Sydenham understood the need for careful bedside observation of clinical phenomena. His attitude towards his contemporaries was indifferent or scornful and he complained bitterly of the opposition and rejection of his own colleagues. His painstaking observations and excellent description of many diseases were recorded in his Observationes Medicae (Medical Observations) (1676). His fame largely rests on his first hand account of diseases including hysteria and his description of chorea minor. He was a sufferer from gout and his treatise on this subject Tractatus de podagra (1683) is considered a masterpiece. The Dissertatio Epistolaris (1682) contains his classic account of hysteria. Sydenham's description of chorea minor, which he saw as a kind of convulsion, is found in his Schedula Monitoria (1686).

Sydenham was one of the first to prescribe iron for anaemia and he popularised the use of quinine yielding cinchona bark introduced from Peru in the treatment of ague or malaria. Syphilis he treated by mercurial inunctions until free salivation occurred and he believed that it was the salivation, rather than the mercury, that wrought

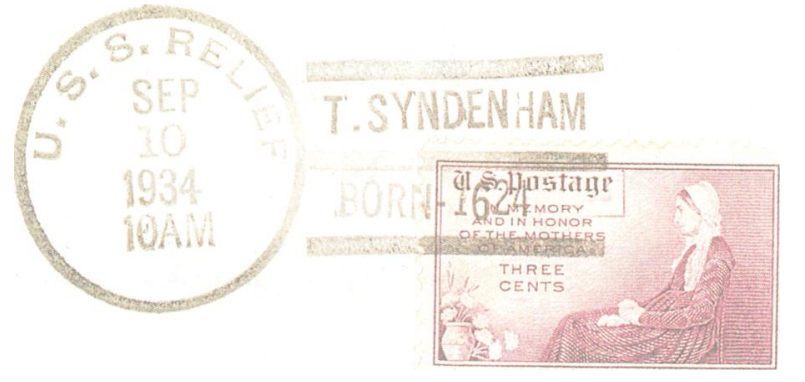

the cure. Opium was a favourite drug in the form of a tincture to which he added saffron, cloves, and cinnamon. "Sydenham's laudanum" as it was called remained a popular remedy for many years. His service to medicine was not to speculate but to lead people back to the bedside. His great success as a physician led Boerhave, when lecturing in Leyden, always to raise his hat on mentioning the name of Sydenham. He had a dignified ethical regard for his patients, holding himself "answerable to God" for their care. This may not have fitted easily into a modern management environment, but his comment "I have consulted my patients' safety and my own reputation most effectually by doing nothing at all" would, no doubt, have been looked upon more favourably.

After he left All Souls College he moved to London where he spent the rest of his life in private practice. Although he has not been honoured postally, he was honoured in this United States postmark of 1934, 310 years after his death. The postmark contains a spelling error. $\mathrm{He}$ died at his house in Pall Mall and was buried in St James's Church, Piccadilly, where the College of Physicians, in 1810 , erected a tablet to his memory. 